\title{
English syllabification as the interaction of markedness constraints"
}

\author{
T. A. Hall \\ Indiana University
}

The present study offers an Optimality-Theoretic analysis of the syllabification of intervocalic consonants and glides in Modern English. It will be argued that the proposed syllabifications fall out from universal markedness constraints - all of which derive motivation from other languages - and a language-specific ranking. The analysis offered below is therefore an alternative to the traditional rule-based analyses of English syllabification, e.g. Kahn (1976), Borowsky (1986), Giegerich (1992, 1999) and to the Optimality-Theoretic treatment proposed by Hammond (1999), whose analysis requires several language-specific constraints which apparently have no cross-linguistic motivation.

\section{Introduction}

Consider the syllabification of the following (broadly transcribed) English words:
(1) lazy $[\mathrm{le}[\mathrm{zi}]$
patron $[\mathrm{pe}[\mathrm{t}[\mathrm{n} \rrbracket$
bulky [b $\Lambda 1 . k i]$

Although the parsings indicated in (1) are in line with universal principles to be made explicit below, there is a surprising lack of consensus in the literature on English phonology that words like the ones in (1) are syllabified as indicated. For example, while Giegerich (1992) syllabifies phonologically similar words of English as in (1), Kahn (1976) proposes an algorithm for the assignment of syllable structure which makes the /z/ in lazy and the /t/ in patron (but not the /l/

\footnotetext{
* Thanks are due to Susanne Fuchs, Antony Green, Silke Hamann, Christiane Kaden, Evan Mellander and Marzena Zygis for their comments on earlier versions of this article. All disclaimers apply.
} 
in bulky) ambisyllabic. Hammond (1999) - whose parsings are similar to the ones in Selkirk (1982) - proposes an Optimality-Theoretic analysis of English in

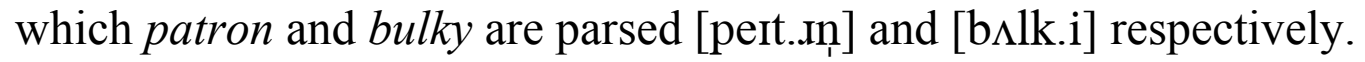

Any study of syllabification in a single language needs to accomplish three general goals, namely to show that (i) the proposed parsings are supported by various phonological generalizations from the language in question, (ii) the arguments that have been proposed by alternate syllabifications can be reanalyzed in other ways, and (iii) the mechanism whereby segments are parsed into syllables is in line with universal principles. The present study offers an Optimality-Theoretic (henceforth OT; Prince and Smolensky 1993) analysis of syllabification in Modern English - in particular General American - in which the goals in (i)-(iii) are accomplished.

The present treatment is significant for several reasons. First, as indicated in the title, I argue that the proposed syllabifications (as in 1) fall out from universal markedness constraints - all of which derive motivation from other languages - and that syllabification is a process occurring in the surface which does not require steps in a derivation. My analysis can therefore be considered to be an alternative to the traditional rule-based analyses of English syllabification, e.g. Kahn (1976), Gussenhoven (1986), Borowsky (1986), Giegerich (1992), Rubach (1996), and most recently Giegerich (1999). My analysis can also be seen as an alternative to the OT treatment proposed by Hammond (1999), whose analysis requires several language-specific constraints which apparently have no cross-linguistic motivation.

This article is organized as follows. In $\S 2$ I present two syllable-based generalizations in English phonology which can be used as reliable tests for how intervocalic clusters should be parsed. In that section I posit an alignment constraint capturing one of these generalizations (ALIGN-30) which is required in my analysis of English syllabification in $\S 4$ and $\S 5$. In $\S 3$ I posit well-known markedness constraints pertaining to syllable structure and onset well-formedness. $\S 4$ consists of a formal analysis of the syllabification of sequences of intervocalic consonants as in (1). In that section I demonstrate that syllabification can be accomplished given the seven constraints posited in $\S 2$ and $\S 3$ and a language-specific ranking. In $\S 5$ I discuss the syllabification of intervocalic sequences of consonants and glides and show that English requires reference to an additional markedness constraint penalizing sonorant plus palatal glide onsets (* ${ }_{\square}[\mathrm{SG})$. In §6 I compare my OT analysis with the one proposed by Hammond (1999) and show that his alternate syllabifications are problematic and that his arguments for these parsings can be analyzed in other ways. $\$ 7$ concludes. 


\section{Two syllable-based generalizations}

In this section I introduce two syllable-based generalizations from English which I refer to below as evidence for and against various syllable parsings. These two generalizations are the distribution of the allophones of $/ \mathrm{p} \mathrm{t} \mathrm{k} /$, especially glottalization (in §2.1), and the distribution of superheavy syllables (in $§ 2.2$ ).

\subsection{Allophones of $/ \mathrm{p} \mathrm{t} k /$}

The following data illustrate that the glottalized allophones of $/ \mathrm{p} \mathrm{t} \mathrm{k/}\left(=\left[\mathrm{p}^{\square} \mathrm{t}^{\square} \mathrm{k}^{\square}\right]\right)$ occur word-finally (in 2a) and as the first $\mathrm{C}$ in word-medial clusters like the ones in (2b). I follow earlier authors who have argued that the two contexts in (2) can be collapsed into syllable-final (or, alternatively, rhymal) position (see, for example, Kahn 1976: 84ff., Gussenhoven 1986, Nespor and Vogel 1986: 77-78, Giegerich 1992: 220-221, Jensen 1993: 298ff., and Kenstowicz 1994: 69). See my analysis in $\$ 4.3 .2$ below, where I show how the clusters in (2b) are heterosyllabified.

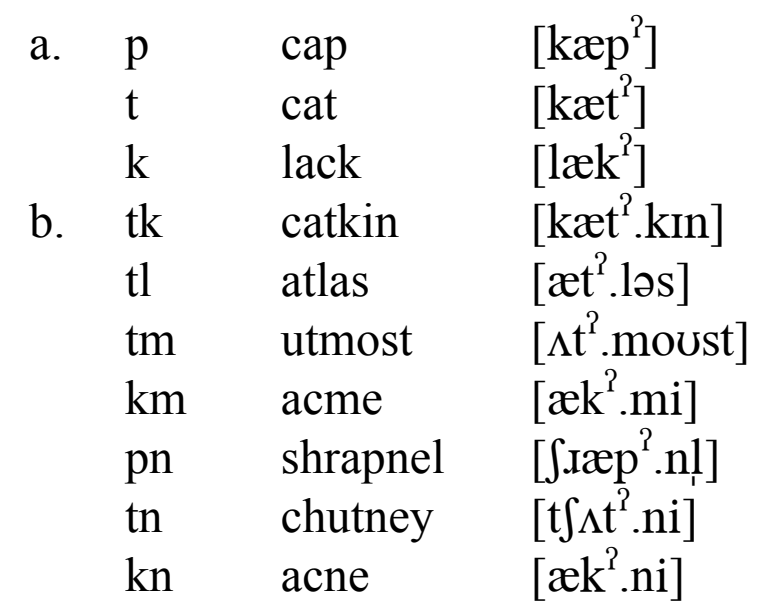

The important point is that if $/ \mathrm{p} \mathrm{t} \mathrm{k} /$ are glottalized then it follows that they are in syllable-final position. ${ }^{1}$

Some linguists argue that the rule required for the aspirated and flapped allophones also makes reference to syllable structure (e.g. Kahn 1976). I assume - following earlier treatments of Kiparsky (1979), Jensen (2000) and Davis and

1 I account for the occurrence of $\left[p^{\square} t^{\square} k^{\square}\right]$ in rhymal position as the consequence of an undominated constraint licensing the (nondistinctive) feature [+release] in syllable-initial position. If only unreleased segments like $[\mathrm{p} \mathrm{t} \mathrm{k}]$ are glottalized then $[\mathrm{p} \mathrm{t} k]$ in the rhyme surface as $\left[p^{\square} t^{\square} k^{\square}\right.$. Since the constraints required in the analysis just described do not bear directly on the syllabification of intervocalic consonant clusters I ignore them here. 
Cho (2003) - that $/ \mathrm{p} \mathrm{t} \mathrm{k/} \mathrm{are} \mathrm{aspirated} \mathrm{in} \mathrm{foot-initial} \mathrm{position,} \mathrm{e.g.} \mathrm{the} / \mathrm{t} / \mathrm{in}$ a word like attain (/[te[n/) is aspirated because it is parsed [Q.(t[e[h) $\left.)_{\mathrm{F}}\right]$. I also assume an analysis for Flapping like the one proposed in Kahn (1976), according to which $/ \mathrm{t} d /$ are flapped when ambisyllabic. Although I do not present a formal analysis in the present article which predicts which intervocalic C's are made ambisyllabic (e.g. the /t/ in later) I provide some remarks in $\S 4.2$ on what a possible treatment might look like.

\subsection{Superheavy syllables}

A second syllable-based generalization for English can be gleaned from the examples in (3) (from Hall 2001), in which the distribution of superheavy $(=\mathrm{VXC})$ syllables is summarized. The ' $\mathrm{X}$ ' in $\mathrm{VXC}$ is a variable ranging over $\mathrm{C}$ (= consonant), $\mathrm{G}$ (=glide) and V (= vowel); hence VXC syllables subsume VLC (e.g. seem), VGC (e.g. house), and VCC (e.g. farm).

(3) a. Three contexts in which superheavy (=VXC) syllables occur:

context $\quad V X C$

(i) before a word boundary arm

(ii) before a compound boundary arm-chair

(iii) before $-\mathrm{CV}(\mathrm{C})$ suffixes doubt-ful

b. One context in which VXC cannot occur: context $\quad V X C$

(i) morpheme-internal *arel.ba

In (3a) we see that VXC syllables occur word-finally (in i), before a compound boundary (in ii) and before consonant-initial suffixes (in iii). By contrast, VXC generally does not occur within morphemes (see $3 b$ ). In morpheme-internal position heavy (i.e. VX) syllables occur regularly, e.g. ego, garden. ${ }^{2}$

In Hall (2001) it is argued that the stem in the three contexts in (3a) constitute separate phonological (=prosodic) words and that the evidence for the prosodic parsings required for words with the phonological and morphological

2 The generalizations in (3) are also discussed by other authors, but their analyses differ from the one I adopt below. For example, Borowsky $(1986,1989)$ argues that the distribution of VXC falls out if the final $\mathrm{C}$ in a word is extrasyllabic and if the morphological rules of English are situated in two distinct lexical levels. Hammond (1999) captures the distribution of English VXC by adopting unconventional syllabifications, as I show in $\S 6$ below. Harris (1994) proposes a Government Phonology analysis of English which accounts for the distribution of VXC. See Hall $(2001,2002)$ for criticisms of Borowsky $(1986,1989)$ and $\S 6$ for criticisms of Hammond. 
structure in (3a) correlates with independent evidence based on allomorphy in English morphology (see Raffelsiefen 1999). Given the prosodic constituent phonological word, the descriptive generalization can be made in (4a), which captures the facts in (3). This generalization is expressed formally with the constraint in (4b), which says that the right edge of a superheavy syllable (analyzed in Hall 2001 as trimoraic) aligns with the right edge of a phonological word.

(4) a. A superheavy syllable must occur at the end of a phonological word.

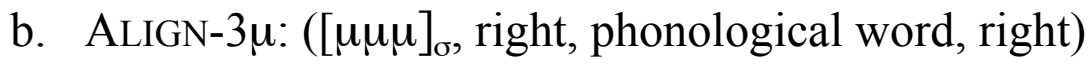

Nonoccurring examples like *areelba, *agelmda violate ALIGN-3 $\square$ because a trimoraic syllable would be internal to a pword.

There are two sets of systematic exceptions to (4) which I mention here because of their relevance to the following analysis: (i) $\mathrm{VLC}_{\mathrm{a}} \cdot \mathrm{C}_{\mathrm{b}} \mathrm{V}$ (e.g. chamber, shoulder, fealty), and (ii) $\mathrm{VC}_{\mathrm{a}} \mathrm{C}_{\mathrm{b}} \mathrm{CV}$ (e.g. empty, antler) occur iff $\mathrm{C}_{\mathrm{a}} \mathrm{C}_{\mathrm{b}}$ is a sequence of nasal or liquid plus homorganic stop. Hall (2001) argues that the $\mathrm{VLC}_{\mathrm{a}}$ and $\mathrm{VC}_{\mathrm{a}} \mathrm{C}_{\mathrm{b}}$ sequences in (i) and (ii) are parsed exceptionally as bimoraic and that they therefore satisfy ALIGN-3 $\square$.

Although the bulk of the work in syllabifying intervocalic consonant clusters is accomplished with the markedness constraints I posit in $\S 3$, I show in $\S 4$ and $\S 5$ that ALIGN-3 $\square$ is also necessary to rule out various incorrect forms. Since ALIGN-3 $\square$ refers to moraic structure the output forms in the tableaus I posit need to contain moraic structure in addition to the segmental structure. For reasons of space I refrain from presenting nonlinear structures and simply refer the reader to Hall $(2001,2002)$ for a treatment of the moraic structure of Modern English. In the analysis below the constraint ALIGN-3 $\square$ will be understood to be violated in a VCC.CV sequence, provided that the syllable-final CC cluster is not a stop plus homorganic nasal or lateral.

The upshot of the preceding discussion is that the generalization expressed in (4) pertaining to the distribution of VXC syllables and in (2) concerning the distribution of the glottalized allophones can be used as a test for the parsings of intervocalic consonant clusters.

\section{$3 \quad$ Markedness constraints}

In this section I posit several well-known markedness constraints pertaining to syllable structure which are required in order to syllabify sequences of intervocalic consonants and glides.

Four universal markedness constraints are posited in (5) (from Prince and Smolensky 1993, after Jakobson 1962, and Venneman 1988): 
(5) a. ONSET: Syllables have onsets.

b. NoCODA: The syllable is open

c. NOCOMPONSET: At most one segment occurs syllable-initially

d. NoCompCoDA: At most one segment occurs syllable-finally.

All four constraints are blatantly violated in the surface in many English words. Two sample words and the respective violations of the four constraints in (5) are presented in (6):

(6)
example
constraints violated
ink [.Шk.]
OnsET, NoCODA, NoCOMPCODA
blink [.bl凹k.]
NoCompOnset, NoCodA, NoCompCodA

Clearly English ranks the faithfulness DEP-V and MAX-C (see McCarthy and Prince 1995) in (7a) which prevent the insertion of vowels and the deletion of consonants respectively higher than the constraints in (5). This ranking is stated in (7b), where I refer to the two constraints in (7a) collectively as FAITH.

(7) a. DEP-V: A vowel in the output corresponds to a vowel in the input. MAX-C : A consonant in the input corresponds to a consonant in the Output.

b. FAITH » NoCOMPOnSET, NoCoda, NoCompCoda, OnSET, NoCoda

The ranking in (7b) accounts for why English words with marked margins can

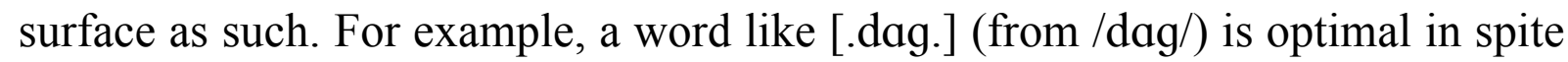
of the NoCODA violation because MAX-C and DEP-V are satisfied. By contrast, candidates like [.dD. T..] or [.dD.] - despite being in line with NoCODA - lose out because they violate DEP-V and MAX-C respectively. Since faithfulness constraints as in (7a) are not important in my analysis I ignore them in the remainder of this article.

In addition to the constraints in (5), any analysis of English requires a constraint which accounts for onset well-formedness. Occurring onsets like the ones in (8a) would satisfy this constraint, while the ones in (8b-c) would not:
a. $[\mathrm{t}$ [ trip ${ }_{\square}[\mathrm{pl}$ play ${ }_{\square}[\mathrm{pj}$ puny
b. $*_{\square}[\mathrm{tt}$ ${ }^{*}[\mathrm{lp}$ $*[j \mathrm{p}$
c. $\quad *{ }_{0}[\mathrm{tl}$
${ }^{*}[\mathrm{tn}$
${ }^{*}[\mathrm{nj}$

The well-formedness of the clusters in (8a) and the ill-formedness of the ones in (8b) is clearly a function of sonority, given the Sonority Hierarchy in (9) (see Clements 1990 for a similar version and Selkirk 1984, Vennemann 1972 , 
Hooper 1976, and Dogil and Luschützky 1990 for earlier ones) and the constraint in (10) (from Selkirk 1984: 116):

(9) SONORITY HiERARCHY ('>' = 'more sonorous than'):

vowels $>$ glides $>$ rhotics $>$ laterals $>$ nasals $>$ fricatives $>$ stops

(10) Sonority Sequencing Generalization (SSG):

"In any syllable, there is a segment constituting the syllable peak that is preceded and/or followed by a sequence of segments with progressively decreasing sonority values".

However, an examination of the ill-formed onset clusters in $(8 \mathrm{c})$ reveals that the constraint governing onset well-formedness cannot simply be the SSG alone because these sequences are well-formed with respect to sonority. For purposes of the present article I require a constraint referring to ONSET WeLLFORMEDNESS (OSW), which can be thought of as an abbreviation for the SSG in (10) or as the constraints ruling out sequences like the ones in (8c). The list in (8c) is not intended to be complete. Some additional restrictions that fit into this category will be discussed in the course of my analysis.

(11) ONSET WELL-FORMEDNESS (OWF):

A cluster of two or more consonants or glides in syllable-initial position must conform to the SSG or to the constraints in (8c).

See Green (2003), who shows that the constraints governing onset wellformedness can occupy different niches in various language-specific constraint hierarchies. In the present treatment of English there is no reason for assuming that the SSG and the constraints in (8c) need to be split up in this way and therefore I refer to all of them collectively as OWF. ${ }^{3}$

\section{$4 \quad$ Syllabification of intervocalic consonant clusters}

\subsection{Introduction}

In this section I present a formal OT treatment of the syllabification of intervocalic clusters of consonants of English. In my analysis I divide the consonant sequences into three categories, as exemplified in (12). Here and

3 The ill-formedness of onset clusters like $t l$ and $t n$ in $(8 \mathrm{c})$ is sometimes attributed to the LAW OF INITIALS, which Vennemann (1988: 32) formalizes as follows: "Word-medial syllable heads are the more preferred, the less they differ from possible word-initial syllable heads of the language system". (The term "syllable head" is synonomous with "syllable-initial cluster"). For OT treatments of English in which the LAW OF INITIALS is assumed see Raffelsiefen (1999) and Hall (2001). 
below ' $\mathrm{C}$ ' stands for a consonant, and ' $\mathrm{V}$ ' represents a syllable peak (i.e. short vowel, syllabic sonorant, long vowel, diphthong). Unless otherwise noted the data are drawn from General American English.
(12) a. V.CV sequences:
V.CV (e.g. lazy)
b. V.CCV sequences: tautosyllabic CC clusters: V.CCV (e.g. patron) heterosyllabic CC clusters: VC.CV (e.g. bulky)
c. $\mathrm{VCCC}(\mathrm{C}) \mathrm{V}$ sequences: $\begin{array}{ll}\text { VC.CCV } & \text { (e.g. empress) } \\ \text { VC.CCCV } & \text { (e.g. instrument) }\end{array}$

In $§ 4.2-\S 4.4$ I discuss words like the ones in (12a-c) respectively. The most significant point I make below is that the variable parsings in (12a-c) fall out from the constraints in $\S 2$ and $\S 3$ and a language-specific ranking.

In the following analysis I only consider word-internal and not acrossword syllabification. I also do not discuss the alignment constraints needed to account for the domain of syllabification (e.g. only within but not across each part of compounds). As I note below, many previous analyses of English have argued that certain intervocalic consonants are ambisyllabic (e.g. Kahn 1976). Since the generalizations I capture in my treatment can be done so without ambisyllabicity, I do not attempt to posit constraints and rankings which predict its occurrence. However, at several points in the following sections I mention why ambisyllabicity is often posited and suggest how my analysis could be modified to accommodate the additional data.

\subsection{The syllabification of $\mathrm{VCV}$}

In this section I show that VCV is always parsed as V.CV and that this syllabification is a consequence of two universal markedness constraints ONSET and NoCODA.

The English examples in (13) contain a VCV sequence. In (13a) the first vowel is long and in (13b) it is short.

$$
\begin{array}{lll}
\multicolumn{2}{l}{\text { VLCV }} & \text { VDCV } \\
\hline & \text { ego } & {[\mathrm{i} D \square \mathrm{o}]} \\
\mathrm{p} & \text { open } & {[\mathrm{o} \square \mathrm{p} \square \mathrm{n}]} \\
\mathrm{z} & \text { lazy } & {[1 \mathrm{e} \square \mathrm{zi}]}
\end{array}
$$




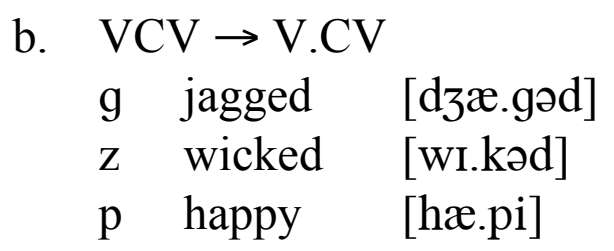

There are two reasons why I syllabify the words in (13) as V.CV (as opposed to VC.V). First, the $\mathrm{C}$ in this context is never glottalized if it is $/ \mathrm{p} \mathrm{t} \mathrm{k}$. And second, the parsing VC.V would violate the generalization in (4) governing the distribution of superheavy syllables when the first $\mathrm{V}$ is long. ${ }^{4}$

The parsings in (13) fall out from the markedness constraints ONSET and NoCoDA in (5a-b). This point is illustrated in the tableau in (14) for lazy.

a.

\begin{tabular}{l||c:c|} 
& ONSET & NOCODA \\
\hline \hline$\square[1 \mathrm{e} \square \mathrm{zi}]$ & & \\
\hline$[\mathrm{le}$.. $\mathrm{i}]$ & $* !$ & $*$ \\
\hline
\end{tabular}

The ranking between the two constraints ONSET and NOCODA is not crucial, since the incorrect form in (14b) is penalized twice and the winner in (14a) not at all. $^{5}$

It should be noted that the syllabification V.CV in (14) is predicted to be correct regardless of the stress pattern of the word; hence in the present analysis V.CV is also selected as optimal when the second vowel bears prominence (e.g. about). Some authors (e.g. Kahn 1976, Gussenhoven 1986) have argued that

4 Some linguists have argued that the intervocalic $\mathrm{C}$ in words like the ones in (13b) should be ambisyllabic because short vowels like [ $[$ ] otherwise only occur in closed syllables (see, for example, Giegerich 1992: 172, Hammond 1999). If this is a true syllable-based generalization then one could either analyze the post-short vowel $\mathrm{C}$ in words like happy as ambisyllabic (Giegerich 1992) or as a geminate consonant (Hammond 1999). I leave these two possibilities open for further study. The nonglottalization of an ambisyllabic/ geminate consonant follows from the proposals made through the years on 'geminate inalterability', e.g. Hayes (1986).

5 Note that words which end in / $\mathrm{tn} \square$ are also predicted to syllabify as V.CV, e.g. eaten as [iDtn】 Words like eaten are apparently problematic for my analysis because the (syllableinitial) $/ \mathrm{t} /$ surfaces as $\left[\mathrm{t}^{\mathrm{Q}}\right]$ (recall from $\$ 2.2$ that the glottalized allophones only surface syllable-finally). I maintain that the predicted parsing [iDtn凹] is correct and that the $/ \mathrm{t} /$ is glottalized because - as the first part of a nasally released stop - it must by definition be orally unreleased (see Ladefoged 1993: 53 for discussion of nasally released stops in English - in his terminology 'nasal plosion'). From a formal point of view the reason $/ \mathrm{t} / \mathrm{in}$ $/ \mathrm{tn} \square$ sequences is unreleased is a consequence of an (undominated) constraint saying that $/ \mathrm{tn} \square$ sequences are nasally released stops. A precise formalization of this constraint exceeds the goals of the present paper. 
English has stress-dependent rules of ambisyllabification referred to in $\S 2.2$ above (which are not to be confused with the non-stress related argument for ambisyllabicity described in note 4). In the present analysis I concentrate solely on the constraints responsible for tauto- or heterosyllabifying intervocalic sequences and not on the ones which might be needed to create ambisyllabic structures. However, for the sake of thoroughness I conclude this section with some brief remarks on the motivation for stress-dependent ambisyllabicity and what an analysis thereof might look like.

Following Kahn (1976) (and Gussenhoven 1986) the generalization is that within English words the $\mathrm{C}$ in $\mathrm{V}(\mathrm{L}) \mathrm{CV}$ is ambisyllabic if the second $\mathrm{V}$ is unstressed. This type of ambisyllabicity is said to be confirmed by native speaker intuitions and is simultaneously argued to be the environment for Flapping, i.e. $/ \mathrm{t} d /$ in American English are flapped only when ambisyllabic. (However, see Steriade 2000: 325ff. for an OT constraint for Flapping which does not make reference to ambisyllabicity.) For example, in the two words later and attain only the $/ \mathrm{t} /$ in the former item is analyzed as ambisyllabic (given its stress pattern) an hence flapped. One could treat the C in LV(LCV as ambisyllabic given an OT analysis like the one proposed by Green (1997) for Irish, who posits a constraint called CloseConTACT - inspired by Trubetzkoy's Silbenschnittkorrelation - according to which a $\mathrm{C}$ within a foot (i.e. in $\mathrm{VN}$ (LCV) is tautosyllabic with the first vowel. If CLOSECONTACT outranks NoCoDA (see tableau 16), then the ambisyllabic candidate would be selected as the optimal one. ${ }^{6}$

\subsection{The syllabification of VCCV}

In this section I argue that two adjacent intervocalic consonants are parsed either tauto-syllabically (i.e. syllable-initially), e.g. [t]] in patron, or heterosyllabically, e.g. [lk] in falcon. The alternate parsings fall out from the seven markedness constraints above and a language-specific ranking.

\footnotetext{
Word-final $/ \mathrm{t} d /$ are also flapped in American English if the following word begins with a vowel, e.g. the /t/ in meet Ann (vs. the aspirated /t/ in see Ted). See McCarthy and Prince (1993: 130-131), who argue that a word-final consonant of English is made ambisyllabic by ranking ONSET ahead of an alignment constraint which says that the left edge of a stem coincides with the left edge of a phonological word and a constraint requiring that a phonological word ends in a consonant. Given this ranking the / $\mathrm{t}$ / in meet Ann (but not the $/ \mathrm{t} /$ in see Ted) would be made ambisyllabic and would therefore be flapped.
} 


\subsubsection{Tautosyllabic CC clusters}

VCCV is parsed as V.CCV in two instances: (i) the CC exhibits a sonority rise (going from left to right) and the $\mathrm{CC}$ is a permissible word-initial cluster of English, or (ii) the CC consists of [s] + voiceless stop.

The English examples in (15) contain an intervocalic CC sequence for category (i) (in 15a) and category (ii) (in 15b). The phonetic transcriptions in (15) and below are broad, unless otherwise noted.

(15)

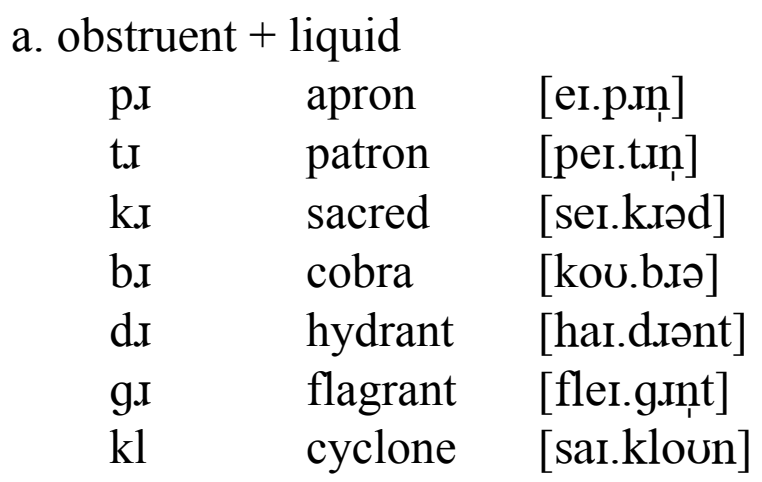

b. $\mathrm{s}+$ voiceless stop:

$\begin{array}{lll}\text { st } & \text { feisty } & {[\mathrm{fa} \square \mathrm{sti}]} \\ \text { sp } & \text { aspect } & {[\square . s p \square k t]} \\ \text { sk } & \text { fiscal } & {[\mathrm{f} \square \text { skl }]}\end{array}$

Recall from note 4 that the consonant following a short vowel (as in the final two examples in 15b) might in fact close the first syllable if this consonant is analyzed as ambisyllabic.

Given the ranking NOCODA » NOCOMPONSET the syllabification in (15a) is correctly predicted to be optimal. This point is illustrated in the tableau in (16) for the word cobra:

\begin{tabular}{|c|c|c|}
\hline & NoCODA & NOCOMPONSET \\
\hline 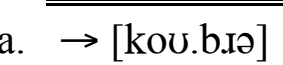 & & * \\
\hline 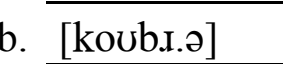 & $* !$ & \\
\hline [koロb.Ш] & $* !$ & \\
\hline
\end{tabular}

An examination of this tableau reveals that (16a) is optimal because the closest competitors in (16b-c) violate NoCODA. Note that the same results could be achieved by substituting NoCoDA for ALIGN-3 7 . Although this alternative would work in words like cobra, in which the CC cluster is preceded by a long vowel, it fails to tautosyllabify CC when preceded by a short vowel (see below).

The constraints in (16) also predict that intervocalic /st/ as in (15b) is tautosyllabic. (There is general agreement in English phonology that [sp st sk] 
clusters cannot be heterosyllabified because the [s] consistently blocks the aspiration of the following stop; see, for example, Kahn 1976, Selkirk 1982, Hammond 1999). This syllabification V.stV is illustrated in the tableau in (17) for the word feisty:

\begin{tabular}{|c|c|c|}
\hline & NoCoDA & NOCOMPONSET \\
\hline a. $\quad[\mathrm{fa} \square \mathrm{sti}]$ & & * \\
\hline b. [fa[st.i] & $* !$ & \\
\hline c. $[\mathrm{fa}[\mathrm{s} . \mathrm{ti}]$ & $* !$ & \\
\hline
\end{tabular}

In this tableau we can observe that (17b-c) lose out to (17a) because they are not in line with NoCODA.

The tableau in (18) for the word aspect is important because it shows that the intervocalic $\mathrm{sC}$ cluster is correctly tautosyllabified even if a short vowel precedes:

\begin{tabular}{|c|c|c|}
\hline & NoCODA & NOCOMPONSET \\
\hline a. $\square[0 . s p \square k t]$ & & * \\
\hline b. [पs.p\kt] & *! & \\
\hline c. [ए sp.. $\mathrm{kt}]$ & $* !$ & \\
\hline
\end{tabular}

At first glance, one might assume that the ranking NoCODA » NoCOMPONSET incorrectly predicts that all fricative-stop sequences are parsed V.CCV, i.e. not only the /st/ in feisty but also, for example, the /ft/ in after. I show in $\S 4.3 .2$ below that fricative+stop sequences other than $\mathrm{s}+$ stop are heterosyllabified (i.e. VC.CV) and that this parsing follows from the ranking of two constraints over NoCODA. ${ }^{7}$

7 Antony Green (personal communication) points out that one curious gap suggests that [sp st sk] are actually heterosyllabic: only [st] but not [sp sk] can be preceded by long vowels (e.g. Easter). Given the parsing Vs.pV and Vs.kV the gaps $* \mathrm{~V}[\mathrm{ppV}$ and $* \mathrm{~V}[\mathrm{k} \mathrm{k}$ would follow from the generalization in (4), and VLs.tV would be allowed if the homorganicity restriction discussed in $\$ 2.2$ included not only nasal/liquid + homorganic stop but also fricative+homorganic stop. That VLsp and VLk are also illicit word-finally might then follow from the treatment in Hall (2001), which is independently required to ban other illegal word-final sequences, e.g. *V[k, *V[p.

While I have at present no analysis for [sp st sk] which accounts for both the phonotactic facts described in the preceding paragraph as well as the lack of aspiration of the stop portion, I suggest tentatively that the [s] in intervocalic [sp st sk] is ambisyllabic, although I leave open how a formal analysis would predict such parsings. 


\subsubsection{Heterosyllabic CC clusters}

There are three types of heterosyllabic CC sequences:

(19) a. CC clusters in which the second C is less sonorous than the first (e.g. $/ \mathrm{k} /$ in bulky)

b. $\mathrm{CC}$ clusters in which the second $\mathrm{C}$ is more sonorous than the first and which are not well-formed onsets of English e.g. /t1/ in atlas)

c. CC clusters in which the two C's are equally sonorous (e.g. /pk/ in napkin)

Note that none of the CC clusters in (19a-c) satisfies OwF.

The data set in (20) contains words of the structure (19a). I have placed these words into two groups: (i) sonorant + obstruent sequences (in 20a), and (ii) fricative + stop sequences (in 20b), where the fricative is anything other than [s]. (Examples with [s] plus stop between vowels were discussed in 17-18). As indicated in the phonetic transcriptions, the clusters listed here are analyzed as heterosyllabic.

a. sonorant + obstruent

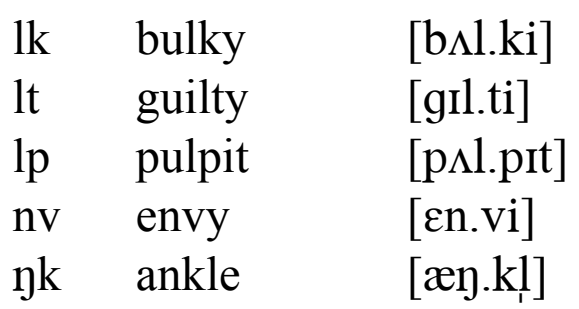

b. fricative (other than $[\mathrm{s}]$ ) + stop

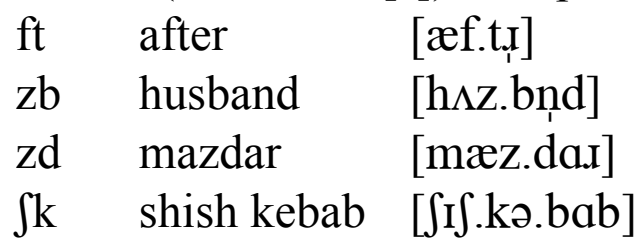

The syllabification VC.CV (as opposed to VCC.V) in (20) derives support from two sets of facts. First, the $/ \mathrm{p} \mathrm{t} \mathrm{k} /$ in the examples in (20) are not glottalized, and second the CC sequences in (20) can only be preceded by short vowels (provided that $\mathrm{CC}$ is nonhomorganic, recall §2.2). Were long vowels permissible in this position, then the otherwise valid generalization in (4) involving the distribution of superheavy syllables would be violated. 
The constraints posited above conspire to predict the correct syllabification for words like the ones in (20a-b), as shown in the tableaux in (21-22) for the words bulky and after respectively:

\begin{tabular}{|c|c|c|c|c|}
\hline & Align-3 & OWF & NoCoDA & NOCOMPONSET \\
\hline a. $\quad[\mathrm{b} \wedge \mathrm{l} . \mathrm{ki}]$ & & & * & \\
\hline$\left[\mathrm{b}_{\Lambda} .1 \mathrm{ki}\right]$ & & $* !$ & & $*$ \\
\hline$[\mathrm{b} \Delta l \mathrm{k} . \mathrm{i}]$ & $* !$ & & * & \\
\hline
\end{tabular}

(22)

\begin{tabular}{|c|c|c|c|c|}
\hline & ALIGN-3ロ & OWF & NoCODA & NOCOMPONSET \\
\hline a. $\quad[\quad[\mathrm{f} . \mathrm{t} \square]$ & & & * & \\
\hline b. [प.ft四 & & $* !$ & & $*$ \\
\hline c. [0 ft. (1] & $* !$ & & * & \\
\hline
\end{tabular}

An examination of these tableaux reveals that the (b) and (c) candidates lose out to the respective (a) forms because they violate either OWF or ALIGN-3 $\square$. Note that the (c) forms also violate the constraint ONSET (recall 5a). The reason ALIGN-3 $\square$ cannot be substituted for ONSET is that for certain words ungrammatical candidates cannot be ruled out without reference to ALIGN-3 $\square$, e.g. candidate (29b) below violates only ALIGN-3 $\square$ but not ONSET.

The additional data in (23) - like the ones in (15a) - contain an intervocalic CC, where the second C is more sonorous than the first $(=19 \mathrm{~b})$. The phonetic transcriptions below are narrow, since they indicate the glottalized allophones of voiceless stops.

$\begin{array}{lll}\text { VCCV } & \text { VC.CV } & \\ \mathrm{tl} & \text { atlas } & {\left[\square \mathrm{t}^{\square} .1 \square \mathrm{s}\right]} \\ \mathrm{tm} & \text { utmost } & {\left[\Lambda \mathrm{t}^{\square} \cdot \mathrm{mo} \mathrm{st}\right]} \\ \mathrm{km} & \text { acme } & {\left[\square \mathrm{k}^{\square} \cdot \mathrm{mi}\right]} \\ \mathrm{pn} & \text { shrapnel } & {\left[\square \mathrm{p}^{\square} \cdot \mathrm{nl}\right]} \\ \mathrm{tn} & \text { chutney } & {\left[\mathrm{tLht}^{\mathrm{a}} \cdot \mathrm{ni}\right]} \\ \mathrm{kn} & \text { acne } & {\left[\square \mathrm{k}^{\square} \cdot \mathrm{ni}\right]}\end{array}$

In contrast to the examples in (15a), the words in (23) are parsed VC.CV and not V.CCV. One piece of evidence that the adjacent consonants in (23) are heterosyllabic is that $/ \mathrm{p} \mathrm{t} \mathrm{k} /$ are glottalized, as indicated in the phonetic transcriptions. A second argument for the heterosyllabification of the clusters in (23) is that the first $\mathrm{C}$ in $\mathrm{CC}$ is consistently preceded by a short vowel (see Hall 2001 for additional examples showing this and for a formal analysis of the VLC.CV gap). Were long vowels permissible in such words then superheavy 
syllables would occur within a phonological word, contrary to the generalization in (4).

A comparison of the obstruent + sonorant consonant sequences in (15a) and (23) reveals a difference between the two: The consonant sequences in the latter words are in line with the SSG in (9), but not with the filters in (8c). These examples therefore show that onset well-formedness cannot be reduced to the SSG alone. Consider the tableau for the word chutney, which is a representative example of the words in (23):

\begin{tabular}{|c|c|c|c|c|}
\hline & ALIGN-3ロ & OWF & NoCODA & NOCOMPONSET \\
\hline a. $\quad$ [t[ht.ni] & & & * & \\
\hline b. [t[h.tni] & & $* !$ & & * \\
\hline c. $[\mathrm{t}[\mathrm{htn} . \mathrm{i}]$ & $* !$ & & * & \\
\hline
\end{tabular}

In this tableau we see the same results as in the ones in (21-22): Candidate (24a) wins out because the two closest competitors are not in line with OWF and Align-3 $\square$.

The final set of data in this section involves a sequence of two intervocalic C's which are equally sonorous $(=19 \mathrm{c})$, as in (25). Here we see combinations of two stops (in 25a), two fricatives (in 25b), and two nasals (in 25c).

VCCV $\square$ VC.CV

a. stop + stop

$\begin{array}{lll}\text { pt } & \text { optical } & {[\square \mathrm{p} . \mathrm{t} \square \mathrm{kl} \rrbracket} \\ \mathrm{kt} & \text { actor } & {[\square \mathrm{k} . \mathrm{t} \square} \\ \mathrm{pk} & \text { napkin } & {[\mathrm{n} \square \mathrm{p} . \mathrm{k}[\mathrm{h}]}\end{array}$

b. fricative + fricative

sf asphalt [ [ $\mathrm{s}$ s.fDlt $]$

c. nasal + nasal

mn amnesty [ [ m.n..sti]

$\mathrm{nm}$ enmity [[n.m[Di]

I parse words like the ones in (25) as VC.CV for two reasons. First, the first C can be glottalized if it is a voiceless stop ${ }^{8}$ and second, the CC clusters in (25) can only be preceded by short vowels. Again, gaps such as [VRk.tV] and [VIm.nV] follow from (4).

8 As pointed out by Kahn (1976), the glottalization of American English /t/ occurs more readily than the glottalization of $/ \mathrm{p} /$ and $/ \mathrm{k} /$. For this reason the glottalization of $/ \mathrm{p} /$ and $/ \mathrm{k} /$ in the examples in (24a) is not always obvious to many native speakers. 
The analysis presented up to this point correctly selects the parsing VC.CV in (25) as optimal, as illustrated in the tableau in (26) for napkin:

\begin{tabular}{|c|c|c|c|c|}
\hline & ALIGN-3ロ & OWF & NoCODA & NoCOMPONSET \\
\hline [n] p.k[h] & & & * & \\
\hline b. $[\mathrm{n} \square . \mathrm{pkh}]$ & & $* !$ & & $*$ \\
\hline$[\mathrm{n} \square \mathrm{pk} . \mathrm{h}]$ & $* !$ & & * & \\
\hline
\end{tabular}

Again, the first candidate in this tableau wins out over the final two because it satisfies the highest two constraints.

To summarize, the constraints ALIGN-3 $\square$ and OWF, when ranked over NoCoDA, correctly syllabify all of the English data presented up to this point. Note too that these constraints account for the principle referred to in the literature as Onset Maximization, i.e. a sequence VCCV is parsed V.CCV only if $\mathrm{CC}$ is a possible onset of the language in question.

\subsection{The syllabification of VCCCV and VCCCCV}

In this section I examine the syllabification of (monomorphemic) English words containing three or four intervocalic consonants. (There are apparently no examples with five or more adjacent consonants). The data are divided into four categories, which have been summarized in (27):

(27) a. $\mathrm{C}_{\mathrm{a}} \mathrm{C}_{\mathrm{b}} \mathrm{C}_{\mathrm{c}}$ clusters in which $\mathrm{C}_{\mathrm{b}} \mathrm{C}_{\mathrm{c}}$ are well-formed onsets of English and in which $\mathrm{C}_{b} \mathrm{C}_{\mathrm{c}}$ rise in sonority (from left to right)

b. $\mathrm{C}_{\mathrm{a}} \mathrm{C}_{\mathrm{b}} \mathrm{C}_{\mathrm{c}}$ clusters in which $\mathrm{C}_{\mathrm{b}} \mathrm{C}_{\mathrm{c}}$ are not well-formed onsets of English and in which $\mathrm{C}_{b} \mathrm{C}_{c}$ rise in sonority (from left to right)

c. $\mathrm{C}_{\mathrm{a}} \mathrm{C}_{\mathrm{b}} \mathrm{C}_{\mathrm{c}}$ clusters in which $\mathrm{C}_{\mathrm{b}} \mathrm{C}_{\mathrm{c}}$ form a sonority plateau

d. $\mathrm{C}_{\mathrm{a}} \mathrm{C}_{\mathrm{b}} \mathrm{C}_{\mathrm{c}} \mathrm{C}_{\mathrm{d}}$ clusters

All occurring three member clusters of English will be shown to belong to one of $(27 \mathrm{a}-\mathrm{c}) .{ }^{9}$ I show below that $(27 \mathrm{a}-\mathrm{b}, \mathrm{d})$ can be syllabified given the ranking ALIGN-3马, OWF » NoCodA shown above. Context (27c) will be shown to require the constraint ONSET.

9 Note that there are a number of gaps, e.g. there are no $C_{a} C_{b} C_{c}$ clusters in which $C_{c}$ is less sonorous than $\mathrm{C}_{b}$ and $\mathrm{C}_{\mathrm{b}}$ is less sonorous than $\mathrm{C}_{\mathrm{a}}$, but where $\mathrm{C}_{b} \mathrm{C}_{\mathrm{c}}$ is not a well-formed onset (e.g. the hypothetical [ $\mathrm{lmta}]$ ). Such gaps are not important for the present analysis and will therefore be ignored. See Hall (2001), who shows that these gaps often follow from the generalization in (4). 


\subsubsection{Three member clusters $(=27 a)$}

The following words illustrate (27a). In the first column we see the relevant sequence and on the corresponding line of the second column a representative example. These words can have either a nasal (in 28a) or a liquid (in 28b) as the first C.

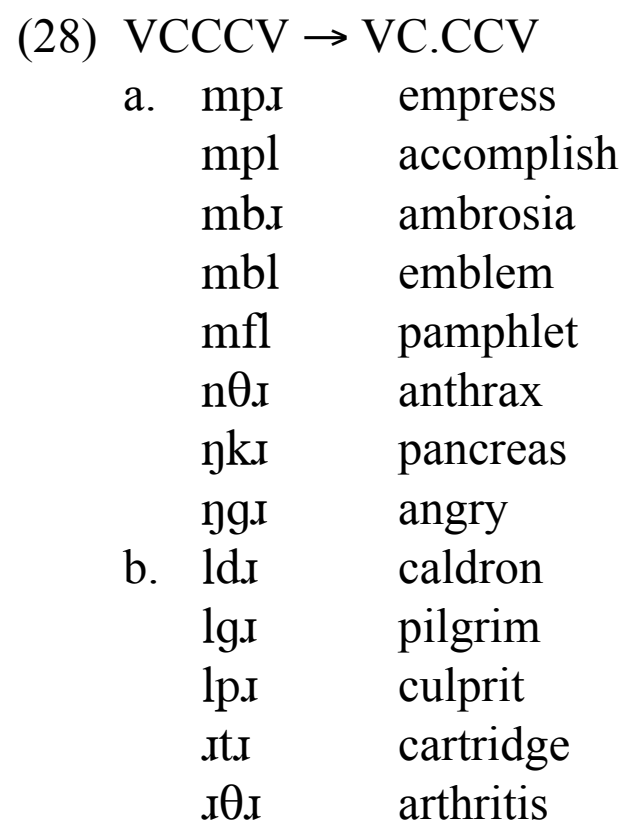

I analyze the syllabification of all of the words in (28) as VC.CCV. Language specific support for this parsing (as opposed to the syllabification VCC.CV) comes from the distribution of the glottalized allophones of $/ \mathrm{p} \mathrm{t} \mathrm{k} /:$ since the second $\mathrm{C}$ in the clusters in (28) never surfaces as glottalized (if it is a voiceless stop) we can conclude that it must be syllable-initial and not syllable-final. The generalization in (4) can also be used as a diagnostic for the parsing as indicated in (28) (and against the syllabification VCC.CV), since the first V in VC.CCV can only be short, provided that the adjacent C's are nonhomorganic (recall $\S 2.2)$.

Given the constraints posited above my analysis correctly syllabifies the words in (28) as VC.CCV. This is illustrated in the tableau in (29) for the word pilgrim:

\begin{tabular}{|c|c|c|c|c|}
\hline & ALIGN-3ロ & OWF & NoCoDA & NOCOMPONSET \\
\hline a. $\quad[\mathrm{pQ} .0 \amalg \mathrm{m}]$ & & & ** & * \\
\hline b. [pप्.णm] & $* !$ & & $* *$ & \\
\hline c. $[\mathrm{p} \square 10 \square \mathrm{m}]$ & & $* !$ & $*$ & $*$ \\
\hline 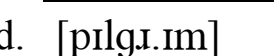 & $* !$ & & ** & \\
\hline
\end{tabular}


Candidates (29b, d) lose out because they violate ALIGN-3 $\square$ and (29c) because it is not in line with OWF.

The following examples contain intervocalic $\mathrm{CCC}$ sequences in which all three segments are obstruents. Like the clusters in (27) the ones in (30) illustrate (26a).

$\begin{array}{ll}\text { (30) } & \text { VCCCV } \\ \text { ksp } & \text { VC.CCV } \\ \text { kst } & \text { extend } \\ \text { pst } & \text { capstan }\end{array}$

Given the constraints above the words in (30) are syllabified as indicated. This is shown in tableau (31) for the word extend:

\begin{tabular}{|c|c|c|c|c|}
\hline & ALIGN-3ロ & OWF & NoCODA & NOCOMPONSET \\
\hline a. $\square$ [[k.st $\square n d]$ & & & $* *$ & $*$ \\
\hline b. [पkst!nd] & & $* !$ & * & * \\
\hline c. [पks.t】nd] & $* !$ & & ** & \\
\hline d. [Lkst.Ind] & $* !$ & & $* *$ & \\
\hline
\end{tabular}

Forms $(31 \mathrm{c}, \mathrm{d})$ are clearly less harmonic than (31a) because they violate ALIGN$3 \square$ and (31b) violates OWF.

\subsubsection{Three member clusters $(=27 b)$}

The following words illustrate intervocalic $\mathrm{C}_{a} \mathrm{C}_{b} \mathrm{C}_{c}$ clusters in which $\mathrm{C}_{b} \mathrm{C}_{c}$ are not well-formed onsets of English and in which $\mathrm{C}_{b} \mathrm{C}_{c}$ rise in sonority (from left to right) $(=27 b)$ :

$\begin{array}{ll}\text { (32) } & \text { VCCCV } \square \text { VCC.CV } \\ \text { ntl } & \text { antler } \\ \text { ntn } & \text { vintner } \\ \text { ndl } & \text { chandler }\end{array}$

Since the $/ t /$ in the first three examples is (optionally) glottalized before a nasal or a lateral (see Kahn 1976), we can conclude that the syllabification indicated in (32) is correct. Recall from $\$ 2.2$ that the VCC sequences in (32) do not violate (4) because the first two C's consist of a nasal or liquid plus a homorganic stop (cf. empty). 
The syllabification VCC.CV in (32) obtains given the constraints above. This is illustrated in the tableau in (33) for the word antler, which is representative of (32):

\begin{tabular}{|c|c|c|c|c|}
\hline & ALIGN-3ロ & OWF & NoCODA & NOCOMPONSET \\
\hline a. $\quad[\mathrm{Qnt} .1 \mathrm{M}]$ & & & $*$ & \\
\hline b. $[\square$ n.t1! & & $* !$ & * & * \\
\hline c. [0.nt1四 & & $* !$ & & $*$ \\
\hline d. [untl.u & $* !$ & & * & \\
\hline
\end{tabular}

In this tableau we see that (33b-d) are less harmonic than (33a) because they violate either OWF or ALIGN-3 ${ }^{10}$

The tableau in (33) is important because it illustrates why ALIGN$3 \square$ cannot be substituted for NoCOMPCODA. Were NoCOMPCODA the highest ranked constraint in (33) then the winner in (33a) would incur a violation due to the [nt] cluster in the coda of the first syllable and candidate (33b) would incorrectly be selected as optimal. See below for additional examples of English words which can only be successfully syllabified with ALIGN-3 $\square$ and not NoCOMPCODA. This being said, it will be demonstrated in $\$ 5.2 .1$ below that my analysis must refer to NOCOMPCODA to account for the syllabification of VCCjV.

\subsubsection{Three member clusters $(=27 c)$}

The words in (34) consist of three intervocalic consonants $C_{a} C_{b} C_{c}$ in which $C_{b} C_{c}$ exhibit a sonority plateau and therefore illustrate $(27 \mathrm{c})$. Note that $\mathrm{C}_{b} \mathrm{C}_{\mathrm{c}}$ is also not in line with OwF.

$\begin{array}{ll}\text { VCCCV } & \text { VCC.CV } \\ \text { mpt } & \text { empty } \\ \mathrm{mpk} & \text { pumpkin } \\ \mathrm{mpt} \square & \text { sumptuous } \\ \square \mathrm{kt} \square & \text { juncture } \\ \square \mathrm{kt} & \text { plankton }\end{array}$

10 The one three member cluster like the ones in (32) which I have omitted is [Ctn], e.g. partner. Since the $[t]$ is glottalized in such examples the parsing is VCC.CV. From a purely descriptive point of view this example does not conform to the generalization in (4a). Since words like partner are idiosyncratic exceptions to (4a) my analysis is not intended to explain them. 
I analyze the syllabification of the words in (34) as VCC.CV - a parsing which derives support from the fact that the second $\mathrm{C}$ can surface as glottalized if it is $/ \mathrm{p} \mathrm{t} \mathrm{k} /$. Recall from $\$ 2.2$ that words like empty are systematic exceptions to Align-3 $\square$ because the first two C's in these five sequences are homorganic.

The syllabification VCC.CV in (34) is correctly selected as optimal given the constraints above, as illustrated in the tableau in (35) for empty. Examples like this one are important because they illustrate the necessity of the constraint ONSET, which must be ranked below OWF but is unranked with respect to NoCODA:

\begin{tabular}{|c|c|c|c|c|c|}
\hline & ALIGN-3ロ & OWF & ONSET & NoCODA & NOCOMPONSET \\
\hline a. $\quad$ [Dmp.ti] & & & * & $*$ & \\
\hline b. [D.mpti] & & $* !$ & * & & * \\
\hline c. [Dm.pti] & & $* !$ & $*$ & $*$ & $*$ \\
\hline d. [Dmpt.i] & & & $* * !$ & $*$ & \\
\hline
\end{tabular}

In this tableau we see that $(35 b-c)$ are not optimal because they violate OWF. A comparison of the winner in (35a) with the closest competitor in (35d) reveals that the latter one loses out to the former because it incurs two ONSET violations. (Note that the addition of ONSET to the constraint hierarchy does not effect the outcome in the tableaux presented above.)

\subsubsection{Four member clusters $(=27 d)$}

Hammond (1999: 83) notes that there are few examples of English words with four intervocalic consonant clusters in which these consonants are tautomorphemic. Some examples are provided in (36). Two types of examples which in the present analysis consist of four separate consonants are listed in (36):

VCCCCV $\square$ VC.CCCV

a. nsk $\mathrm{conscript}$

nst? instrument

1st $\square$ maelstrom

b. kst $\square$ extra

kspl explain

bst $\square$ abstract

kskl exclaim 
The tableau in (37) for instrument shows how the correct syllabification in (36) obtains:

\begin{tabular}{|c|c|c|c|c|c|}
\hline & ALIGN-3믈 & OWF & ONSET & NoCODA & NOCOMPONSET \\
\hline 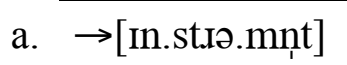 & & & $*$ & $* *$ & $*$ \\
\hline b. [पhs.tW.mnt] & $* !$ & & * & ** & * \\
\hline c. [Ghst.⿴.mnt] & $* !$ & & $*$ & $* *$ & \\
\hline d. [Gst口. (.mnt] & $* !$ & & $* *$ & $* *$ & \\
\hline e. [पnst四nnt] & & $* !$ & * & * & * \\
\hline
\end{tabular}

In this tableau it is illustrated that the two top ranked constraints ALIGN-3 $\square$ and OWF suffice to rule out the final four forms.

\section{Syllabification of $\mathrm{VC}(\mathrm{CC}) \mathrm{GV}$}

I treat the syllabification of $\mathrm{VC}(\mathrm{CC}) \mathrm{GV}$ separately because it does not follow from the constraints in the preceding sections alone. It will be shown below that intervocalic $\mathrm{C}(\mathrm{CC}) \mathrm{G}$ clusters can be correctly syllabified give the ranking

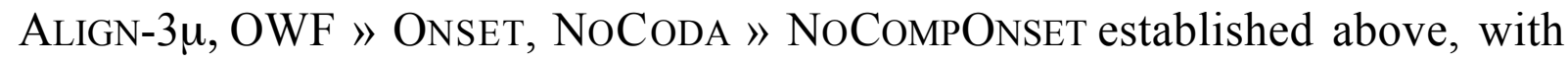
the addition of a constraint barring sonorant consonant plus glide onsets (i.e. $*_{\square}[\mathrm{SG})$ and NoCOMPCODA.

\subsection{The syllabification of VCGV}

VCGV words have been divided into three categories, as shown in (38):

(38) a. VCGV sequences in which C is a stop, where CG is a well-formed onset (e.g. opulent with [pj])

b. VCGV sequences in which $\mathrm{C}$ is anything but a stop and in which $\mathrm{CG}$ is not a well-formed onset (e.g. onion with [nj])

c. VCGV sequences in which $\mathrm{C}$ is anything but a stop and in which $\mathrm{CG}$ is a well-formed onset (e.g. amulet with [mj]).

I discuss first (38b), followed by (38a) and then (38c). ${ }^{11}$ Context (38c) will be shown to require the constraint $*_{\square}[\mathrm{SG}$ referred to above.

11 Note that there is a fourth logical possibility in (38), namely VCGV sequences in which C is a stop, where CG is not a well-formed onset. No clear examples of such CG sequences seem to exist in English. One possible example is [ $[\mathrm{j}]$, which is attested in the rare word gules and as an optional pronunciation for gubernatorial. In the following analysis I assume that $[\mathrm{Dj}]$ is a wellformed onset cluster of English. 


\subsubsection{VCGV sequences in which $C$ is not a stop (=38b)}

The following words contain intervocalic $\mathrm{CG}$ sequences in which the $\mathrm{C}$ is not a stop and in which CG is not a well-formed onset, i.e. [nj $\mathrm{lj} \mathrm{Cj}]$ and [lw] in American English. ${ }^{12}$ As indicated in (39) I analyze intervocalic [nj lj] as heterosyllabic - following earlier studies on English phonology (e.g. Borowsky 1986, Jensen 1993) - even though the V.CGV parsing is not obviously bad from the point of view of syllable markedness. ${ }^{13}$

$\begin{array}{ll}\text { VCGV } & \text { VC.GV } \\ \mathrm{nj} & \text { onion } \\ \mathrm{lj} & \text { million } \\ \mathrm{Cj} & \text { erudite } \\ \mathrm{lw} & \text { always }\end{array}$

In most of the examples discussed below the glide in $\mathrm{VC}(\mathrm{CC}) \mathrm{GV}$ is [j], since there are often few or no examples with [w].

12 Note that there are no $\mathrm{Cj}$ sequences in American English in which the $\mathrm{C}$ is a coronal, i.e.

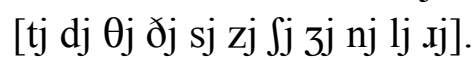

13 Borowsky (1986) and Jensen (1993) posit the Vn.jV and Vl.jV parsing (when the first vowel is stressed) to account for the fact that the [j] in $\mathrm{VnjV}$ and $\mathrm{VljV}$ deletes in certain dialects when the second vowel is stressed, e.g. volume (with [j]) vs. voluminous (without the [j]) and continue (with [j]) vs. continuity (without the [j]). Thus, if these dialects ban syllable-initial [lj nj], the deletion of [j] in voluminous and continuity is a consequence of the parsing VDljV and VDnjV. (It should be noted here that many speakers of American English pronounce voluminous and continuity with the [j]; see also Kenyon and Knott 1953).

In the present analysis it is unclear how to account for the stress-conditioned 'resyllabification' of [A.B] to [.AB], as described in the preceding paragraph. Note that it only occurs when A $\square[1 \mathrm{n}]$ and $B$ is [j], whereas other syllable contacts remain unaffected. For example, heterosyllabic [t.l] is not converted to a [tl] onset when the following vowel is stressed because the $/ \mathrm{t} /$ is consistently glottalized, regardless of the stress pattern, cf. the /t/ in atlas, Atlanta, which is realized in both words as glottalized. I therefore assume for speakers of the dialect in which no [j] is realized in words like voluminous and continuity the existence of a constraint guaranteeing that V.njV and V.ljV are optimal given the existence of stress on the second vowel. At present I have no explanation for why there should be a constraint nor can I say whether or not it is attested in other languages.

That the sequences [nj] and [1j] in (39) can be preceded by long vowels, e.g. union, amonia, begonia, failure, peculiar, suggests that the parsing V.CGV is correct. See Hall (2001), who attributes the occurrence of long vowels before $\mathrm{njV}$ and $\operatorname{ljV}$ to the fact that $[\mathrm{n}$ $1 \mathrm{j}]$ are all coronal. 
The following tableau for the word onion shows that the correctly syllabified output form is selected as optimal given the constraints presented in the preceding sections:

a.

\begin{tabular}{l||c|c|c|c|c|} 
& ALIGN-3 $\square$ & OWF & ONSET & NOCODA & NOCOMPONSET \\
\hline \hline$\square[\Lambda \mathrm{n} . \mathrm{jn} \rrbracket$ & & & $*$ & $*$ & \\
\hline b. & & $* !$ & $*$ & & $*$ \\
\hline
\end{tabular}

The winner in (40a) is more harmonic than (40b) because the latter one violates OWF. ${ }^{14}$

\subsubsection{VCGV sequences in which C is a stop (=38a)}

The examples in (41) contain VCGV sequences in which the $\mathrm{C}$ is a stop, and in which CG is a well-formed onset cluster of (American) English. (These clusters subsume [pj bj kj $\mathrm{dj} \mathrm{kw} \mathrm{gw]).} \mathrm{In} \mathrm{contrast} \mathrm{to} \mathrm{the} \mathrm{examples} \mathrm{in} \mathrm{(39),} \mathrm{I} \mathrm{analyze} \mathrm{CG}$ as tautosyllabic in such words. There are no sequences of CG in American English in which the $\mathrm{C}$ is [t] or [d] (recall note 12).

$\begin{array}{ll}\text { (41) } & \text { VCGV } \\ \text { pj } & \text { V.CGV } \\ \mathrm{bj} & \text { tabulent } \\ \mathrm{kj} & \text { accurate } \\ \mathrm{gj} & \text { regular } \\ \mathrm{kw} & \text { equity } \\ \mathrm{\square w} & \text { jaguar }\end{array}$

The reason the words in (41) are parsed V.CGV and not as VC.GV is that the stop is never glottalized if it is voiceless. Further evidence for the tautosyllabic parsing in (41) is that long vowels can occasionally be found before CG sequences when the $\mathrm{C}$ is a voiceless or voiced stop. Examples have been provided in (42): ${ }^{15}$

14 In varieties of English in which [nj lj] are well-formed (e.g. RP news [njuwz]), the treatment presented up to this point predicts that they should be tautosyllabic in intervocalic position (e.g. [ $\Lambda . n j n \rrbracket$ for onion). See §5.1.3. In that section I show that the constraint $*_{\square}[\mathrm{SG}$ correctly heterosyllabifies examples like onion in British English.

15 The number of examples like the ones in (42) is small, however. Another peculiarity regarding these words is that the only long vowels permitted before $\mathrm{CG}$ are [i[ and [u[. I leave open whether or not this is systematic or accidental.

The commonly occurring mispronunciation of the word nuclear as [nulkj]l四lends further support to my claim that long (high) vowels can precede CG. 
(42) Long vowels before stop-glide sequences:

pj scrupulous

bj tubular, zebu

$\mathrm{kj} \quad$ nucule

gj rugulous

$\mathrm{kw} \quad$ equal, sequence, sequel

It should also be noted here that RP allows long vowels before [tj] and [dj] sequences which are absent in American English, e.g. mutual [mjuDtjwDl].

In the tableau in (43) for the word opulent I have shown that the correctly parsed forms in (41) and (42) are selected by the constraint rankings presented up to this point:

a.

\begin{tabular}{l||l|l|l|l|c|} 
& ALIGN-3 & OWF & ONSET & NoCODA & NOCOMPONSET \\
\hline \hline$\square$ [प.pju.lnt] & & & $*$ & $*$ & $*$ \\
\hline$[\square$ p.ju. $\ln ]]$ & & & $*$ & $* * !$ & \\
\hline
\end{tabular}

In contrast to the previous examples in this section, the winner in (43) can only be selected by considering the low ranked constraint NoCoDA.

\subsubsection{VCGV sequences in which $C$ is not a stop $(=38 c)$}

The following words contain VCGV sequences in which $\mathrm{C}$ is anything but a stop and in which CG is not a well-formed onset. These sequences are restricted to [fj vj mj]. As indicated in (44) I analyze CG as heterosyllabic, even though the V.CGV parsing is not obviously bad from the point of view of syllable markedness.

$\begin{array}{ll}\text { (44) } & \text { VCGV } \\ \mathrm{fj} & \text { nC.GV } \\ \mathrm{vj} & \text { purview } \\ \mathrm{mj} & \text { amulet }\end{array}$

The reason I analyze the CG sequences in (44) as heterosyllabic is that the vowel preceding this cluster is (typically) short, as illustrated in (45) below: ${ }^{16}$

16 To my knowledge no study to date has considered the cooccurrence restrictions regarding the vowels which can and cannot occur before CG in English. Impressionistically it seems that there are few English examples of [vj] clusters which are tautomorphemic with the preceding vowel. There is one example to my knowledge of a word with a [vj] cluster which is preceded by a long vowel, namely uvular. Given the word uvular, in which the long vowel [u[ surfaces before [vj], one could either conclude that the generalization in 
(45) Short vowels before $\mathrm{CG}$, where $\mathrm{C}=[\mathrm{f} \mathrm{v} \mathrm{m}]$ :

$\mathrm{mj}$ stimulous, emulate, amulet, amuse

fj effusive, refuge, refuse, diffuse

vj review

Given the generalization concerning the distribution of superheavy syllables in (4) the lack of long vowels before CGV makes sense if CG is heterosyllabic.

The constraints posited up to this point are unable to select the correctly parsed form in (44) and (45). This point is illustrated in the tableau in (46) for the word amulet. (' $\square$ ' represents here and below the incorrect winner)

\begin{tabular}{|c|c|c|c|c|c|}
\hline & ALIGN-3ロ & OWF & ONSET & NoCoDA & NOCOMPONSET \\
\hline [Dm.ju.1Dt] & & & * & **! & \\
\hline 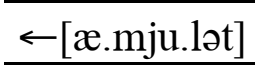 & & & $*$ & * & * \\
\hline
\end{tabular}

In this tableau we see that the intended winner in (46a) and the intended loser in (46b) incur three constraint violations each. (Candidate 46b satisfies OWF because [mj] is a well-formed onset of English, e.g. music).

The tableau in (46) shows that an additional constraint is needed which penalizes certain onset clusters which obey OWF, e.g. [mj]. This constraint has been presented in (47). See Casali (1998: 74-88) and Kiparsky (1998) who posit a general constraint ${ }_{[}[\mathrm{CG}$ on the basis of data from the Benue-Congo language Emai (Nigeria) and Gothic respectively. The constraint in (47) only penalizes ${ }_{\square}\left[\mathrm{CG}\right.$ onsets in which the $\mathrm{C}$ is a sonorant consonant. ${ }^{17}$

${ }_{\square}[\mathrm{SG}$ : Sonorant plus glide in syllable-initial position is prohibited.

Since English allows certain $\mathrm{Sj}$ sequences word-initially (e.g. [mj] in music), ${ }_{\square}[\mathrm{SG}$ is obviously not surface true and must be outranked by the faithfulness constraints (7a).

The reason for the avoidance of SG onsets can be attributed to the observation made by Vennemann (1988) that languages prefer to have onset clusters which are separated by a relatively great sonority value, e.g. [pj] is

(45) is correct and that this is a marked exception, or that long vowels can occur before $\mathrm{Cj}$ if the $\mathrm{C}$ is an obstruent. These are questions I leave open for further research.

17 The constraint* ${ }_{\square}[\mathrm{CG}$ is independently required in languages which allows sequences of obstruent+liquid in the onset but not obstruent+glide.

Jensen (1993: 67) posits an identical constraint for American English, although his reasons are very different than my own. 
preferred to [pn] because the sonority distance between [p] and [i] is greater than the distance between [p] and [n] on the Sonority Hierarchy in $(9) .{ }^{18}$ Vennemann (1988: 14ff.) shows that various synchronic and diachronic patterns are triggered by this tendency, e.g. the historical deletion of $/ \mathrm{g} \mathrm{k} /$ in initial $/ \mathrm{kn} \mathrm{gn} /$ clusters in English (e.g. knee, gnome). I see the avoidance of SG onsets in English in a similar way.

The addition of ${ }_{[}[\mathrm{SG}$ to the constraints posited above correctly predicts that the optimal form for the words in (44) is selected. This point is illustrated in the tableau in (48) for the word amulet.

\begin{tabular}{|c|c|c|c|c|c|c|}
\hline & ALIGN-3 & OWF & ONSET & ${ }^{\circ}[\mathrm{SG}$ & NoCODA & $\begin{array}{l}\text { NoCOMP } \\
\text { ONSET }\end{array}$ \\
\hline$\square[\square \mathrm{m} . j u .1 \square \mathrm{t}]$ & & & * & & $* *$ & \\
\hline . [.mju.1】t] & & & $*$ & $* !$ & * & * \\
\hline
\end{tabular}

A comparison of tableau (48) with the earlier one in (46) reveals that the addition of the constraint $*_{[}[\mathrm{SG}$ to the hierarchy enables us to select the winner in (48a) over its closest competitor in (48b). The crucial ranking here is that $*_{\square}$ [SG must dominate NoCODA; in (35) below it will be shown that ${ }_{\square}[\mathrm{SG}$ must be ranked below ALign-3 $\square$. (Please note that the addition of ${ }_{\square}[\mathrm{SG}$ to the constraint hierarchy for English does not affect the outcome of the tableaux presented earlier).

Note that candidate (48b) also satisfies OWF in RP, because this dialect has many words beginning with [nj], e.g. news [njuwz] (recall note 14). Candidate (48a) represents the correct syllabification for this dialect to account for the deletion of $/ 1 \mathrm{n} /$ (recall note 12). This candidate is selected because candidate $(48 \mathrm{~b})$ violates ${ }_{\square}[\mathrm{SG}$.

\subsection{The syllabification of $V C C(C) G V$}

In this section I divide $\mathrm{VCC}(\mathrm{C}) \mathrm{GV}$ sequences into the following two categories:

a. $\quad \mathrm{VC}_{\mathrm{a}} \mathrm{C}_{\mathrm{b}} \mathrm{j} \mathrm{V}$ in which $\mathrm{C}_{\mathrm{a}}$ is anything other than $[\mathrm{s}]$

b. $\mathrm{VC}_{\mathrm{a}} \mathrm{C}_{\mathrm{b}}\left(\mathrm{C}_{\mathrm{c}}\right) \mathrm{j} \mathrm{V}$ in which $\mathrm{C}_{\mathrm{a}}$ is $[\mathrm{s}]$

18 Vennemann employs 'strength', which is the converse of 'sonority'. According to his Head Law (1988: 13): „A syllable head [=onset, T. A. H.] is more preferred: ....the more sharply the Consonantal Strength drops from the onset toward the Consonantal Strength of the following syllable nucleus." 
I discuss first (49a) and then (49b). The former context will be shown to require reference to the constraint NoCOMPCODA.

\subsection{1 $V C_{a} C_{b j} V$ in which $C_{a}$ is anything other than $[s](=49 a)$}

The following words consist of $\mathrm{VCCjV}$ sequences. Note that the words are parsed so that only the second $\mathrm{C}$ forms an onset with the glide, thus the constraint * ${ }_{\square}[\mathrm{SG}$ is consistently violated in (50b) but not in (50a). I have divided the words in (50) into two groups. In (50a) we see $\mathrm{VC}_{\mathrm{a}} \mathrm{C}_{\mathrm{b}} \mathrm{V}$ sequences in which $\mathrm{C}_{\mathrm{b}}$ is a stop (50b) in which $\mathrm{C}_{\mathrm{b}}$ is anything other than a stop.
VCCGV $\square$ VC.CGV
a. $\square \mathrm{j}$ argue
$1 \mathrm{kj} \quad$ calculus
mkw cumquat
b. Imj formula
bfj obfuscate

The parsings in (50) derive support from the two generalizations in §2.2. First, the second $\mathrm{C}$ in VCCGV is never glottalized if it a voiceless stop (e.g. the $/ \mathrm{k} / \mathrm{in}$ calculus) and second, the VCC.GV parse would violate (4), since $\mathrm{C}_{\mathrm{a}} \mathrm{C}_{\mathrm{b}}$ are nonhomorganic.

I have provided a tableau below in (51) for the word argue and formula, which are representative of (51a) and (51b) respectively. The example in (52) is important because it shows that ALIGN-3 $\square$ must dominate ${ }_{[}[\mathrm{SG}$.

\begin{tabular}{|c|c|c|c|c|c|c|}
\hline & ALIGN-3ロ & OWF & ONSET & ${ }_{[}[\mathrm{SG}$ & NoCoDA & NOCOMPONSET \\
\hline 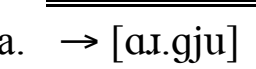 & & & $*$ & & * & * \\
\hline$[\mathrm{QD} . \mathrm{ju}]$ & $* !$ & & * & & * & \\
\hline
\end{tabular}

\begin{tabular}{|c|c|c|c|c|c|c|}
\hline & |ALIGN-3ロ & OWF & ONSET & $*_{n}[\mathrm{SG}$ & NoCODA & NOCOMPONSET \\
\hline a. $\square$ [foLmju.10] & & & & * & $*$ & $*$ \\
\hline b. [fo[m.ju.1D] & $* !$ & & & 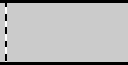 & $*$ & \\
\hline
\end{tabular}

In these tableaux the (a) candidates are optimal because their closest competitors are not in line with ALIGN-3 $\square$.

A final set of data to consider is presented in (53). These words consist of VCCGV, where the adjacent C's are a nasal plus a homorganic stop: 


$\begin{array}{ll}\text { VCCGV } \\ \text { mpj } & \text { VC.CGV } \\ \mathrm{mbj} & \text { ambulance } \\ \square \square \mathrm{j} & \text { angular } \\ \square \square \mathrm{w} & \text { linguist } \\ \square \mathrm{kw} & \text { banquet }\end{array}$

Recall from $\$ 2.2$ above that tautosyllabic VNC sequences are analyzed as bimoraic and not trimoraic, so that the parsing VC.CjV does not violate ALIGN$3 \square$.

The following tableau provides an evaluation of the word computer. The winner in (54a) can only be selected by adding the constraint NoCOMPCODA to the constraint ranking presented up to this point and that this constraint must outrank NoCompOnSET. For reasons of space I do not list ALIGn-3ฤ,OWF, ONSET or ${ }_{[}[\mathrm{SG}$, which are satisfed by both candidates.

a.

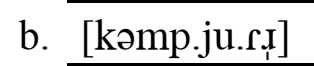

\begin{tabular}{|c|c|c|c|}
\hline & NoCODA & NoCOMPCODA & NOCOMPONSET \\
\hline 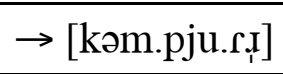 & $*$ & & $*$ \\
\hline [k】mp.ju. 而) & * & $* !$ & \\
\hline
\end{tabular}

An inspection of this tableau reveals that the winner in (54a) and its closest competitor in (54b) are in line with ALIGN-3■, OWF, ONSET, ${ }_{\square}[\mathrm{SG}$ and they incur one violation each of NoCODA.

It is worth noting that certain examples in (50) and (53) would violate the VCC.GV parse for independent (phonotactic) reasons. For example, in cumquat and obfuscate in (50) the parsing VCC.GV is bad because the CC strings are otherwise impermissible codas, i.e. ${ }^{*}[\mathrm{mk}]$ and ${ }^{*}[\mathrm{bf}]$. The same point holds for a word like angular in (53), since there are no English syllables ending in [प]].

\subsection{2 $V C_{a} C_{b}\left(C_{b}\right) j V$ in which $C_{a}$ is $[s](=49 b)$}

Two final data sets have been presented in (55) and (56). In (55) we see VCCjV and in (56) VCCCjV; in both data sets the first $\mathrm{C}$ is an [s]. (There are no examples to my knowledge of words belonging to the latter category in which CCCG are obviously tautomorphemic.) As indicated below the $\mathrm{CC}(\mathrm{C}) \mathrm{G}$ sequence is situated in onset position.

VCCGV $\square$ V.CCGV

skj rescue

spj dispute

skw sesqui- 


\section{(56) VCCCGV $\square$ VC.CCGV}

kskw exquisite

kskj excuse

Evidence for the parsing in (55) and (56) is that the stop portion is never aspirated (recall $\$ 2.2$ in which it was noted that only foot-initial $/ \mathrm{p} \mathrm{t} \mathrm{k/aspirate).}$ Since no aspiration occurs even when the vowel following the glide is primarily stressed (e.g. askew) we can safely assume that the [s] is in onset position.

In (57) I have provided a tableau for the word rescue, which is representative of (55). In (57) and (58) below I only include NOCOMPONSET and not NoCOMPCODA because the winning candidate violates the former constraint and not the latter one.

\begin{tabular}{|c|c|c|c|c|c|c|}
\hline 7) & ALIGN-3 & OWF & ONSET & ${ }^{*}[\mathrm{SG}$ & NoCODA & $\begin{array}{l}\text { NoCOMP } \\
\text { ONSET }\end{array}$ \\
\hline a. $\square$ [Ш.skjuप] & & & & & & $*$ \\
\hline b. [प]s.kju[] & & & & & $* !$ & $*$ \\
\hline c. [पsk.juप] & $* !$ & & & & $*$ & \\
\hline
\end{tabular}

In this tableau (57c) is clearly the least harmonic candidate because it is not in line with ALIGN-3】. The closest competitor to the winner in (57a) is candidate (57b), which is not optimal because it violates NoCoDA.

In (58) I have provided a tableau for the word exquisite, which is representative of (56):

a.

\begin{tabular}{|c|c|c|c|c|c|c|}
\hline & ALIGN-3ロ & OWF & ONSET & ${ }^{*}[\mathrm{SG}$ & NoCODA & $\begin{array}{l}\text { NoCOMP } \\
\text { ONSET }\end{array}$ \\
\hline 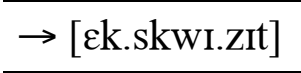 & & & $*$ & & $* *$ & $*$ \\
\hline [Q.kskwLzL] & & $* !$ & $*$ & & $*$ & $*$ \\
\hline [Dks.kw口zL] & $* !$ & & $*$ & & $* *$ & * \\
\hline [Dksk.w口zL] & $* !$ & & $*$ & & $* *$ & \\
\hline
\end{tabular}

In this tableau (58b-d) are less harmonic than the winner in (58a) because they violate either ALIGN-3 $\square$ or OWF.

In (59) I summarize the constraint ranking posited in the preceding analysis: 
(59) Summary of rankings:

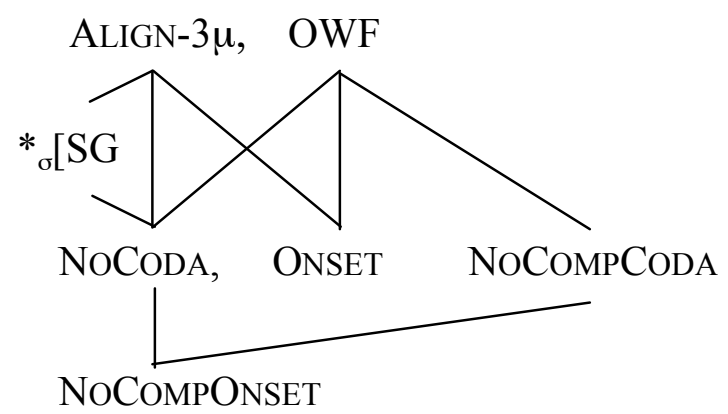

In $\S 4.2$ I suggested that certain consonants in English are ambisyllabic (following the claims made by earlier researchers, e.g. Kahn 1976). If there are indeed ambisyllabic consonants then additional constraints (e.g. Close CONTACT) need to be added to the ranking in (59).

\section{A criticism of Hammond (1999)}

Hammond (1999) has an OT approach to English which differs radically from the one proposed above because he assumes - contrary to tradition in phonology - that codas and not onsets are maximized. ${ }^{19}$ Thus, Hammond proposes that under circumstances to be made explicit below VCV can be parsed VC.V and VCCV as VCC.V. I show here that the generalizations Hammond tries to capture with coda maximization can (and should) be expressed in other ways and therefore reject parsing such as VC.V and VCC.V on principled grounds.

Hammond (1999: 49ff.) argues that the syllabification V.CV is correct unless the $\mathrm{C}$ is $[0]$. In the case of $\mathrm{VDV}$ the consonant is argued to close the first

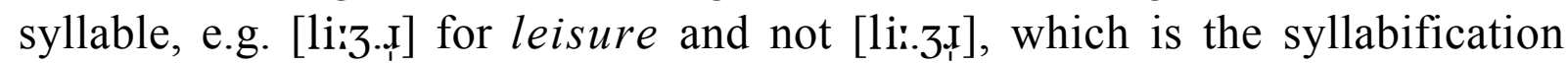
predicted by the analysis in $\S 2$ to be correct. Hammond's argument that VD.V (and not V. .VV) is the correct parsing is based on the distribution of [0], which is summarized in (60):

(60) a. word-final: beige, rouge

b. intervocalic: leisure, seizure, pleasure

c. word-initial: * [पa]

d. postconsonantal: *[Q.]oD]

In (60c-d) we see that $[0]$ is barred from onset position and in (60a) that the same sound can occur as a (word-final) coda. If the $[\square]$ in the intervocalic environment

19 Hammond's coda maximization approach is assumed by some earlier authors for English, e.g. Hoard (1971) and Selkirk (1982). 
in (60b) were syllable-final - so the argument goes - then the generalization is that English [0] cannot occur in the syllable onset. For this reason, Hammond proposes a constraint he calls *ONSET/_ (p. 49), which bars [0] from onset position. Since this constraint outranks ONSET and NoCODA, the optimal syllabification for words like leisure is predicted to be VD.V.

I reject the parsing $\mathrm{VD} . \mathrm{V}$ because it would violate the generalization in (4) if the first $\mathrm{V}$ is long (e.g. in leisure). I hold that the phonotactic facts in (60) can be explained without recourse to the syllabification VD.V (or the constraint *ONSET/_). In order to account for the gaps in (60c-d) we simply need a (positive) constraint stating that $[0]$ occurs only in postvocalic position. Given a purely linear constraint, formulated positively and not negatively, there is no reason for the proposed syllabification VD.V. ${ }^{20}$

According to Hammond the words of the structure in (15) (e.g. patron) and (20) (e.g. bulky) are syllabified differently than in the present analysis. Some examples of specific clusters which are argued to be parsed VCC.V are listed in (61) (Hammond 1999: 133ff.):

(61) VCC.V parsings according to Hammond (1999):

Vlt.V: filter

Vlp.V: pulpit

Vlk.V: falcon

For reasons of space I do not consider the arguments Hammond adduces for all of the two member clusters which he claims have the VCC.V parsing, nor do I consider his arguments for the VC.CV parsing (e.g. for cobra, which I argue is parsed V.CCV). Instead I restrict my discussion to the examples presented in (61) and show how these specific sequences need not have a parsing which is diametrically opposed to the principle of Onset Maximization. I leave open for further study how Hammond's arguments for the VCC.V parsings for other CC clusters or for VC.CV in words like cobra can be reanalyzed so that they are in line with the analysis presented in $\S 4$.

20 See Green (2001: 37ff.) for an OT analysis of the distribution of English [0] which does not assume Hammond's syllable parsings.

The same reasoning can be applied to Hammond's (1999: 51) analysis of the distribution of the velar nasal. Hammond formulates a constraint (p. 51) stating that [ $[$ ] does not occur in the onset, concluding that intervocalic $[\mathrm{Q}]$ is in the coda (e.g. dinghy is parsed [dШ.i]). An alternative is that the constraint expressing the distribution of [ $[$ ] be stated positively: [0] only occurs after a short vowel. Given a constraint along these lines there is no reason to assume the parsing VC.V in words like dinghy. See Green (2001: 37ff.) for an OT constraint capturing the distribution of English [0] which refers to moraic structure. 
Hammond argues that VCC.V is correct for the sequences in (61) because the cooccurrence restrictions governing vowels that can and cannot occur before the relevant consonant cluster is the same (or nearly the same) when the cluster is word-medial and word-final. Consider the following argument for the syllabification Vlt.V (p. 132): Both word-final [1t] and word-medial [1t] cannot be preceded by the two diphthongs $[\mathrm{a} \square \mathrm{C}]$, meaning that there are gaps in English like $*\left[\mathrm{QDT}_{\mathrm{t}}\right]$ and $*[\mathrm{CD} \mathrm{ti}]$. Hammond reasons that gaps like these follow if two assumptions are made:

(62) a. the constraint ruling out [0jlt] and [awlt] is syllable-based

b. medial sequences of [1t] are affiliated to the left: Vlt.V

I reject both assumptions in (62) below.

The final two clusters in (61) also show a coocurrence restriction with the previous vowel which Hammond captures with the VCC.V parsing: The long

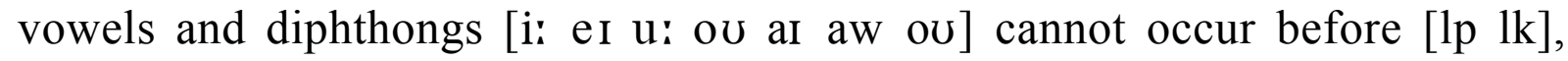
regardless of whether or not [lp $\mathrm{lk}]$ are word-final (in 63a) or word-medial (in $63 b)$.

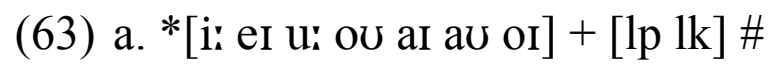

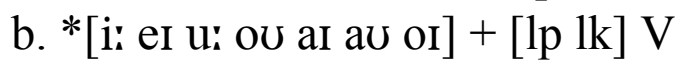

(z.B. $*[\mathrm{a} \square \mathrm{lk}]$ )

(z.B. *[aDlki])

Again, Hammond argues that the gaps in (63) can be ruled out if the constraint ruling out $[\mathrm{a} D \mathrm{lk}]$ etc. is syllable-based (62a), and if medial sequences of more than one consonant are affiliated to the left, i.e. Vlk.V and Vlp.V ( $=62 \mathrm{~b})$.

Hammond argues that the VCC.C parsings for the words in (61) are selected as optimal due to the interaction between various syllable-markedness constraints and a high ranked constraint he calls MAX-CODA, which say that as many consonants should be affiliated to the left as possible when there is more than one (p. 219). If MAX-CODA is ranked ahead of ONSET, we predict the VCC.V parsing in (61), as illustrated in the tableau in (64) for fealty:

(64) Evaluation of fealty after Hammond (1999: 231):

\begin{tabular}{l||c|c|} 
& MAX-CODA & ONSET \\
\hline \hline$[\mathrm{fi}[\mathrm{ti}]$ & $* !$ & \\
\hline$\square[\mathrm{fi}[\mathrm{t} . \mathrm{i}]$ & & $*$ \\
\hline
\end{tabular}


According to Hammond's treatment the parsing VLC.CV loses out over VLCC.V in (64) because the former syllabification violates MAX-CODA and because MAX-CODA is higher ranked than ONSET. ${ }^{21}$

The alternative to Hammond's treatment is to reject both of the assumptions he makes above in (64). Thus, in the case of the [0It] and [aDlt] gaps, one could simply write a highly specific purely linear constraint (i.e. one not referring to the syllable) ruling out the sequences [ $\mathrm{QDt}$ t] and $[\mathrm{aDlt}]$, e.g. $*\left[\mathrm{CL}_{\mathrm{t}}\right] /[\mathrm{a} \square \mathrm{lt}]$. Given the absence of the syllable in this constraint we can therefore parse VltV sequences as Vl.tV and not as Vlt.V. ${ }^{22}$ A linear constraint like the one just described might derive further support from the fact that the diphthongs $[\mathrm{GC}$ and $[\mathrm{a} \mathrm{C}]$ have an additional restriction that has nothing to do with syllable structure: neither of them can be followed by a noncoronal consonant, regardless of whether or not that consonant would be tautosyllabic with the diphthong or in the onset of the following syllable (i.e. there are no

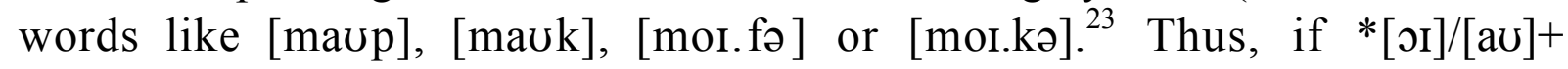
noncoronal is linear, the proposed constraint $*[\mathrm{o}[] /[\mathrm{a} \square]+[1 \mathrm{t}]$ could be linear as well.

Hammond tries to account for the gaps involving vowels before the final two clusters in (61) by maximizing codas, but they can be captured by independent constraints which are in line with onset maximization. Thus, consider (63b). Given the (correct) syllabifications Vl.kV and Vl.pV, the lack of long vowels and diphthongs before the lateral can be seen as a consequence of the generalization stated in (4) above, since the superheavy $\mathrm{V} \square$ sequence in VL.kV and VL.pV is not final in the phonological word. The gaps in (63a) are indicative of a larger gap in English phonotactics, namely VLCC\# is only possible if the final $\mathrm{C}$ is a coronal obstruent (e.g. colt, scold, seems, seemed). Many writers have tried to account for this gap by positing a maximal syllable template for English which can only be exceeded by an (extrasyllabic) coronal

21 Hammond analyzes the VC.CV parsing in examples like cobra as the result of the ranking of MAX-CoDA over NoCoDA, i.e. the winner [koDb.0] is better than [kol.bD] because the latter incurs a fatal violation of the former constraint. The reason [koDb. $⿴$ ] wins out over [ko[bC]] is that the latter form violates a high ranked cover constraint Hammond dubs GoODCODA, which prohibits sequences like $[\mathrm{b}]$ ] in syllable-final position.

22 Technically speaking, the constraint $*[\mathrm{o} \square \mathrm{t}] /[\mathrm{a} \square \mathrm{lt}]$ is not purely linear, since these sequences can occur if they are separated by a word or compound boundary, e.g. ...owl today. In this case the segments in the constraint $*[\mathrm{o} \square \mathrm{t}] /[\mathrm{a} \square 1 \mathrm{t}]$ must belong to the same phonological word. Thus, a string like [aDlt] is permissible only when these segments belong to separate phonological words.

23 The linear constraints described above would also have the advantage that they would not require one to analyze the diphthongs $[\mathrm{a}]$ ] and $[\mathrm{o}[]$ as trimoraic, as suggested by Hammond (1999). 
obstruent. For a recent treatment of these gaps in which no extra-syllabificity is assumed see Hall $(2001,2002)$. While Hammond's treatment of the gaps involving [lp $1 \mathrm{k}]$ has the apparent advantage of being able to capture the *[VПp] and the $*[\mathrm{~V} \square \mathrm{pV}]$ gaps in the same way the cost is that universal Onset Maximization is sacrificed for a language specific constraint maximizing codas. What is equally problematic from a language specific point of view is that Hammond's parsing Vlp.V and Vlk.V cannot account for the fact that $/ \mathrm{p} \mathrm{k} /$ are never realized as glottalized in this environment.

\section{Conclusion}

This article has presented a formal OT analysis of syllabification in Modern English in which the surface patterns follow from seven markedness constraints (including an alignment constraint), all of which are independently motivated in other languages, and a language-specific ranking. The syllabification of intervocalic consonsonant clusters requires the ranking listed in (59).

I have argued above that the proposed analysis is superior to earlier ones (in particular the on proposed by Hammond 1999), in which parsings are assumed which are diametrically opposed to the established principle of Onset Maximization. The reasons for the alternate syllabifications proposed by Hammond (1999) were shown to be compatible with the present analysis.

\section{References}

Borowsky, T. 1986. Topics in the Lexical Phonology of English. Ph.D. dissertation. University of Massachusetts at Amherst [Published 1990: New York: Garland].

Borowsky, T. 1989. Structure preservation and the syllable coda in English. Natural Language and Linguistic Theory 7: 145-166.

Casali, R. F. 1998. Resolving Hiatus. New York: Garland.

Clements, G. N. 1990. The role of the sonority cycle in core syllabification. In: J. Kingston \& M. E. Beckman (eds.) Papers in Laboratory Phonology I: Between the Grammar and Physics of Speech. Cambridge: Cambridge University Press. 283-333.

Davis, S. \& M.-H. Cho 2003. The distribution of aspirated stops and /h/ in American English and Korean: an alignment approach with typological implications. Linguistics 41.4: 607-652.

Dogil, G. \& H. C. Luschützky 1990. Notes on sonority and segmental strength. Rivista di Linguistica 2.2: 3-54

Giegerich, H. 1992. English Phonology. An Introduction. Cambridge: Cambridge University Press.

Giegerich, H. 1999. Lexical Strata in English. Morphological Causes, Phonological Effects. Cambridge: Cambridge University Press. 
Green, A. 1997. The Prosodic Structure of Irish, Scots Gaelic, and Manx. Ph.D. dissertation. Cornell University.

Green, A. 2001. The tense-lax distinction in English vowels and the role of parochial and analogical constraints. Linguistics in Potsdam 16: 32-57.

Green, A. D. 2003. Extrasyllabic consonants and onset well-formedness. In: C. Féry and R. van de Vijver (eds.) The Syllable in Optimality Theory. Cambridge: Cambridge University Press.

Gussenhoven, C. 1986. English plosive allophones and ambisyllabicity. Gramma 10: 119141.

Hall, T. A. 2001. The distribution of superheavy syllables in Modern English. Folia Linguistica XXXV-3/4: 339-442.

Hall, T. A. 2002. Against extrasyllabic consonants in German and English. Phonology 19.1: 33-75.

Hammond, M. 1999. The Phonology of English. A Prosodic Optimality-Theoretic Approach. Oxford: Oxford University Press.

Harris, J. 1994. English Sound Structure. Oxford: Blackwell.

Hayes, B. 1986. Inalterability in CV phonology. Language 62: 321-351.

Hoard, J. 1971. Aspiration, tenseness, and syllabication in English. Language 47: 133-140.

Hooper, J. 1976. An Introduction to Natural Generative Phonology. New York: Academic.

Jakobson, R. 1962. Selected Writings 1: Phonological Studies. Den Haag: Mouton.

Jensen, J. 1993. English Phonology. Amsterdam: Benjamins.

Jensen, J. 2000. Against ambisyllabicity. Phonology 17: 187-235.

Kahn, D. 1976. Syllable-Based Generalizations in English Phonology. Ph.D. dissertation. MIT.

Kenstowicz, M. 1994. Phonology in Generative Grammar. Cambridge: Blackwell.

Kenyon, J. S. \& T. A. Knott 1953. A Pronouncing Dictionary of American English. Springfield: Merriam.

Kiparsky, P. 1979. Metrical structure assignment is cyclic. Linguistic Inquiry 10: 421-441.

Kiparsky, P. 1998. Sievers Law as prosodic organization. In: J. Jasanoff, H. C. Melchert \& L. Oliver (eds.) Mír Curad: Studies in Honor of Calvert Watkins. Innsbruck: Institut für Sprach-wissenschaft der Universität Innsbruck. 345-360.

Ladefoged, P. 1993. A Course in Phonetics. Fort Worth: Harcourt and Brace.

McCarthy, J. \& A. Prince 1993. Generalized alignment. In G. Booij \& J. van Marle (eds.) Yearbook of Morphology 1993. Dordrecht: Kluwer. 79-153.

McCarthy, J. \& A. Prince 1995. Faithfulness and reduplicative identity. In: J. N. Beckman, L. Walsh Dickey and S. Urbanczyk (eds.) Papers in Optimality Theory. Amherst, Mass.: GLSA. 249-384.

Nespor, M. \& I. Vogel 1986. Prosodic Phonology. Dordrecht: Foris.

Prince, A. \& P. Smolensky 1993. Optimality Theory. Ms. Rutgers University and University of Colorado.

Raffelsiefen, R. 1999. Phonological constraints on English word formation. In: G. Booij and J. van Marle (eds.) Yearbook of Morphology 1998. Kluwer. 225-287.

Rubach, J. 1996. Shortening and ambisyllabicity in English. Phonology 13.2: 197-237.

Selkirk, E. O. 1982. The syllable. In: H. van der Hulst \& N. Smith (eds.) The Structure of Phonological Representations. Part I. Dordrecht: Foris. 337-382. 
Sekirk, E. O. 1984. On the major class features and syllable theory. In: M. Aronoff \& R. Oehrle (eds.) Language Sound Structure. Cambridge, Mass.: MIT Press. 107-137.

Steriade, D. 2000. Paradigm uniformity and the phonetics-phonology boundary. In: M. Broe \& J. Pierrehumbert (eds). Papers in Laboratory Phonology 5. Cambridge: Cambridge University Press. 313-334.

Vennemann, T. 1972. On the theory of syllabic phonology. Linguistische Berichte 18: 1-18.

Vennemann, T. 1988. Preference Laws for Syllable Structure and the Explanation of Sound Change. Berlin: Mouton. 